\section{Kin Recognition Alters Root and Whole Plant Growth of Split-root Cycas edentata Seedlings}

\author{
Thomas E. Marler ${ }^{1}$ \\ Western Pacific Tropical Research Center, College of Natural and Applied \\ Sciences, University of Guam, UOG Station, Mangilao, Guam 96923
}

Additional index words. Cycadaceae, Cycas nitida, identity recognition, phenotypic plasticity, root allocation

\begin{abstract}
Split-root techniques were used to determine if Cycas edentata seedling roots possessed identity recognition capabilities. One compartment of the split-root containers contained a competing half-sibling seedling, and the second compartment contained one of four treatments. When the second compartment contained a half-sibling or $C$. edentata seedling from the same habitat, root growth did not differ between compartments. When the second compartment contained a $C$. edentata seedling from a habitat $130 \mathrm{~km}$ away or a $C$. nitida seedling, root dry weight and root length were increased above that of compartments with half-siblings. Whole plant growth also increased in seedlings that experienced competition with the conspecific plant from a distant habitat or from a different species. The results validated the ability of $\mathrm{Cycas}$ edentata roots to recognize and then use a plastic response to neighbor root identity. In horticultural settings, planting cycad plants where neighbors are close relatives may reduce plant growth, and planting to ensure neighbors are not close relatives may increase plant growth.
\end{abstract}

The ability of plants to distinguish self roots and kin roots from non-kin roots is shown in the growing body of research on plant identity recognition. In many species studied to date, roots respond differently to roots of the same individual, roots of a close relative, or roots of non-related competitors (Falik et al., 2003; Gruntman and Novoplansky, 2004; Holzapfel and Alpert, 2003; Mahall and Callaway, 1992, 1996; Maina et al., 2002). These responses are studied in the context of competition reduction among different parts of the same plant or those of a close relative. Kin selection theory is partly founded in the conception that individuals increase their collective fitness by behaving in a manner that increases the fitness of related individuals (Hamilton, 1964a, 1964b). This is realized by reducing investment in competition, which can increase the individual's fitness because fewer resources are consumed for competing with neighbors and can similarly increase the neighbor's fitness through altruism (Axelrod and Hamilton, 1981).

The most prevalent response variables in this body of research are various root growth traits. Other responses to belowground neighbor identity reported to date include plant biochemistry (Broz et al., 2010) and pollen quality (Lankinen, 2008).

Identity recognition capabilities of cycads have not been studied to date. A greater understanding of this phenomenon may be useful for planning the layout of garden and

Received for publication 05 Aug. 2013. Accepted for publication 23 Aug. 2013.

${ }^{1}$ To whom reprint requests should be addressed; e-mail tmarler@uguam.uog.edu. habitat (different habitat); and 4) one $C$. nitida mother tree in the Samar habitat was located $\approx 350 \mathrm{~km}$ to the east and represented competitors from a con-generic population (different species).

The sarcotesta was removed and the cleaned seeds were stored until 25 Aug. 2011, when all seeds were planted in a bed of perlite. The germinated seedlings were removed from the perlite on 3 Oct. 2011. At this stage, a robust taproot from 110 to $120 \mathrm{~mm}$ in length had developed but no leaf growth had ensued (Fig. 1A). The split-root seedlings were crafted by starting with a transverse cut to standardize taproot length to $50 \mathrm{~mm}$ and then by splitting the entire taproot into two halves with a radial longitudinal cut (Fig. 1B). All cuts were made with a razor blade. The split-root containers were created by adjoining two square $0.625-\mathrm{L}$ pots. The split roots were positioned onto the ridge that separated each of the two containers such that each container received half of the split root. The containers were filled with washed river sand. The remainder of the seedlings were planted singly in $1.8-\mathrm{L}$ pots in the same medium and held until the beginning of the competition treatment. The split-root seedlings were grown under $75 \%$ shade for 1 month and then the shadecloth was removed. The nursery bench received $4 \mathrm{~h}$ of morning sun and then filtered shade from a Sandoricum koetjape Merr. tree for the remainder of the photoperiod. The sand was watered daily.

Root competition. Each of the split-root seedlings was bare-rooted to visually inspect root development on 13 June 2012. Seedlings with heterogeneous fine root development in each compartment were retired from the study, and the seedlings with homogeneous amounts of fine roots in the two halves (estimated visually) were re-planted into larger split-root containers with 2.6-L capacity in each half. Seedlings that had been grown singly were bare-rooted and planted as competitors. Every replication received a half-sib competitor in one of the two compartments. The second compartment received one of four seedling types: 1) a half-sib seedling as the control; 2) a $C$. edentata seedling from the same habitat; 3 ) a $C$. edentata seedling from the distant habitat; or 4) a C. nitida seedling (Fig. 1C). All plants were provisioned with $75 \%$ shade for 1 month and then were grown under the ambient light conditions described previously. A completely randomized design was used with four treatments and nine replications, and a border was provided by C. edentata seedlings in single pots.

To maximize root competition, no fertilizer was applied for the duration of the experiment. The river sand medium was impoverished as indicated by soil analyses that revealed total nitrogen was $4.4 \pm 0.6 \mathrm{mg} \cdot \mathrm{g}^{-1}$, available phosphorus was $5.01 \pm 0.49 \mathrm{mg} \cdot \mathrm{kg}^{-1}$, and exchangeable potassium was $20.11 \pm$ $1.02 \mathrm{mg} \cdot \mathrm{kg}^{-1}($ mean $\pm \mathrm{se}, \mathrm{n}=3)$. The plants were irrigated every $2 \mathrm{~d}$ in the absence of rain and maintained until 16 May 2013.

Ending measurements. All three plants in each replication were bare-rooted. The two 
competitor seedlings were not used for measurements and were removed from the experiment. Measurements on the split-root seedling began by counting the number of leaves and number of leaflets for each leaf. Stem height and diameter were measured. Fine roots under $2 \mathrm{~mm}$ in diameter were removed from coarse roots above $2 \mathrm{~mm}$ in diameter, and their length was determined using the line intersect method (Smit, 2000; Tennant, 1975). Length of roots greater than $2 \mathrm{~mm}$ was measured directly. Aboveground components were separated into leaflets, petiole + rachis, or stem sections. Each root compartment was separated into coarse roots, coralloid roots, or fine roots. Each of these sections was dried at $75{ }^{\circ} \mathrm{C}$ in a convection oven and then dry weight was measured. Specific leaf area was calculated from area and dry weight measurements on 10 leaflets and then total leaf area for each replication was calculated from specific leaf area and total leaflet dry weight. Total plant dry weight was calculated by the sum of all components, and the root/shoot proportion was calculated from the components of belowground and aboveground plant parts. The influence of competitor identity on root development was calculated by dividing the dry weight or length for fine roots in the half-sib compartment into dry weight or length for fine roots in the second compartment. For this variable, a value above 1 indicated greater dry weight or length of roots in the second compartment, whereas a value below 1 indicated greater dry weight or length of roots in the half-sib compartment. All response variables were subjected to one-way analysis of variance with four treatment levels and nine replications.

\section{Results}

Considerable root growth occurred in both root compartments for all replications (Fig. 2). The identity of competitor seedling influenced root development within each compartment (Fig. 3). Root length did not differ between the two compartments for the control plants or when the second compartment contained a $C$. edentata seedling from the same habitat. Competition with a $C$. edentata seedling from a distant habitat increased root length $68 \%$, and competition with a $C$. nitida seedling increased root length $82 \%$ above root length in the half-sib compartment. The increased root growth in the compartments with the non-relatives partly came at the expense of root growth in the compartment with the half-sib competitor (Fig. 3).

Total plant growth also responded to identity of the competitor plants (Table 1). Competition with a $C$. nitida seedling in half of the rooting volume increased stem height $33 \%$ and stem diameter $25 \%$ above that of competition with a close relative. Stem growth was not influenced by any of the three treatments in which a $C$. edentata seedling was competing in the second compartment. Similarly, leaves per plant, leaflets per leaf, and total leaf area were increased by competition
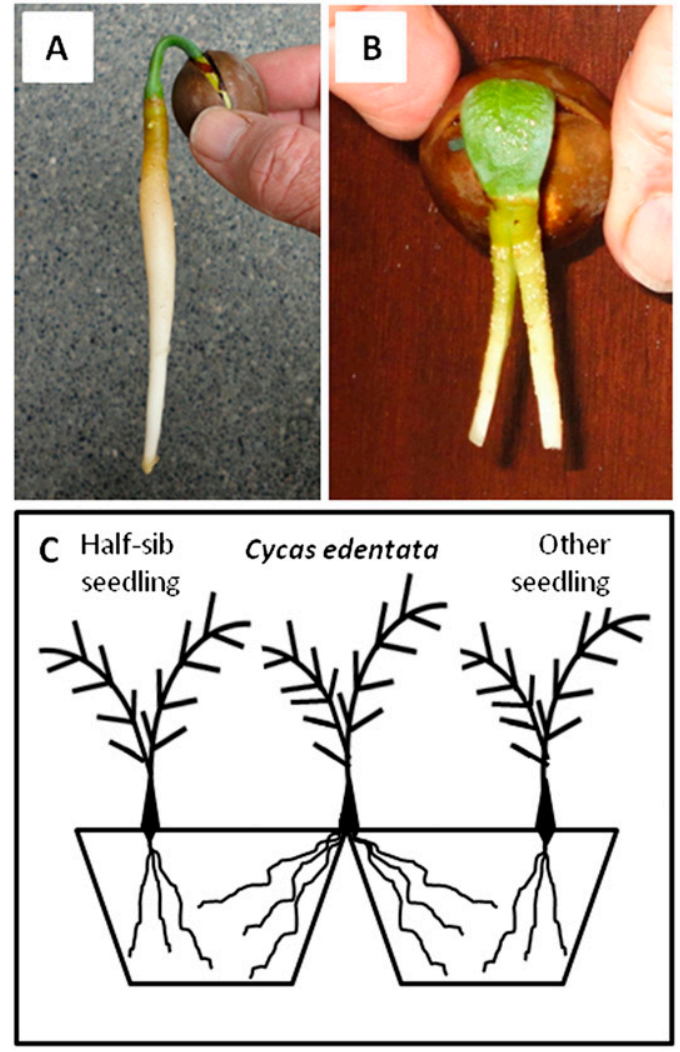

Fig. 1. Preparation of Cycas edentata split-root containers. (A) Recently germinated seedlings were barerooted. (B) Seedling root length was standardized to $50 \mathrm{~mm}$ then split into half. (C) Each split-root seedling was supplied with a seedling of a half-sib competitor in one compartment and one of four competitor treatments in the second compartment.

with a $C$. nitida seedling above that of competition with $C$. edentata seedlings. Total plant dry weight of plants grown in competition with a $C$. edentata seedling from a distant habitat was increased $39 \%$ above that of plants grown in competition with a $C$. edentata from the same habitat. Plants grown in competition with $C$. nitida seedlings accrued dry weight that was $109 \%$ greater than plants grown in competition with a close relative.

The proportion of roots in each of the two compartments did not differ from unity when the second compartment contained a half-sib or a seedling from the same habitat (Table 1). Significant heterogeneity in length or dry weight occurred between the two root compartments when the second compartment contained a con-specific seedling from a distant habitat or a seedling of a different species. In contrast to this plastic response of altering root growth in the two compartments, the proportion of dry weight deployed to belowground tissues in relation to dry weight deployed to aboveground components was not influenced by competitor seedling identity (root-to-shoot overall mean 0.46). Other root traits that were not responsive to competitor identity were specific root length (overall mean $\left.=894 \mathrm{~cm} \cdot \mathrm{g}^{-1}\right)$ and coralloid root dry weight (overall mean $=772 \mathrm{mg}$ per plant).

\section{Discussion}

This is the first look at the influence of belowground competition on root traits for

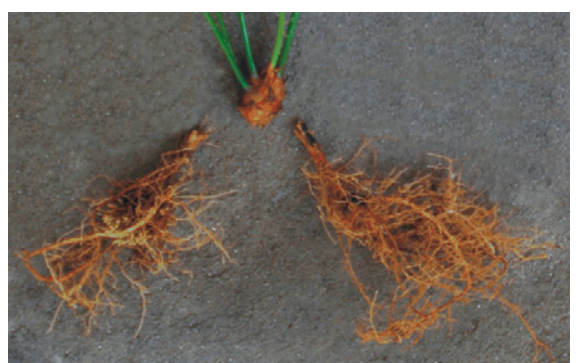

Fig. 2. General appearance of Cycas edentata seedling roots after competition with a halfsibling in the left compartment and a C. edentata seedling from a distant habitat in the right compartment.

any cycad species. I asked a precise question in this study. When confronted by roots of a half-sib, a seedling from a nearby mother, a con-specific seedling from a distant habitat, or a seedling from a different Cycas species, can $C$. edentata roots recognize identity of the competitor roots? The results unambiguously show that roots of this representative cycad species indeed possess the ability to recognize kin. Based on the current study, we cannot determine if this ability is a unique trait for Cycas edentata, or if it is known for other Cycas species or for other cycad genera.

Understanding the belowground processes of cycad plants is of fundamental and applied interest. In natural habitats, seed vectoring is negligible for most contemporary 


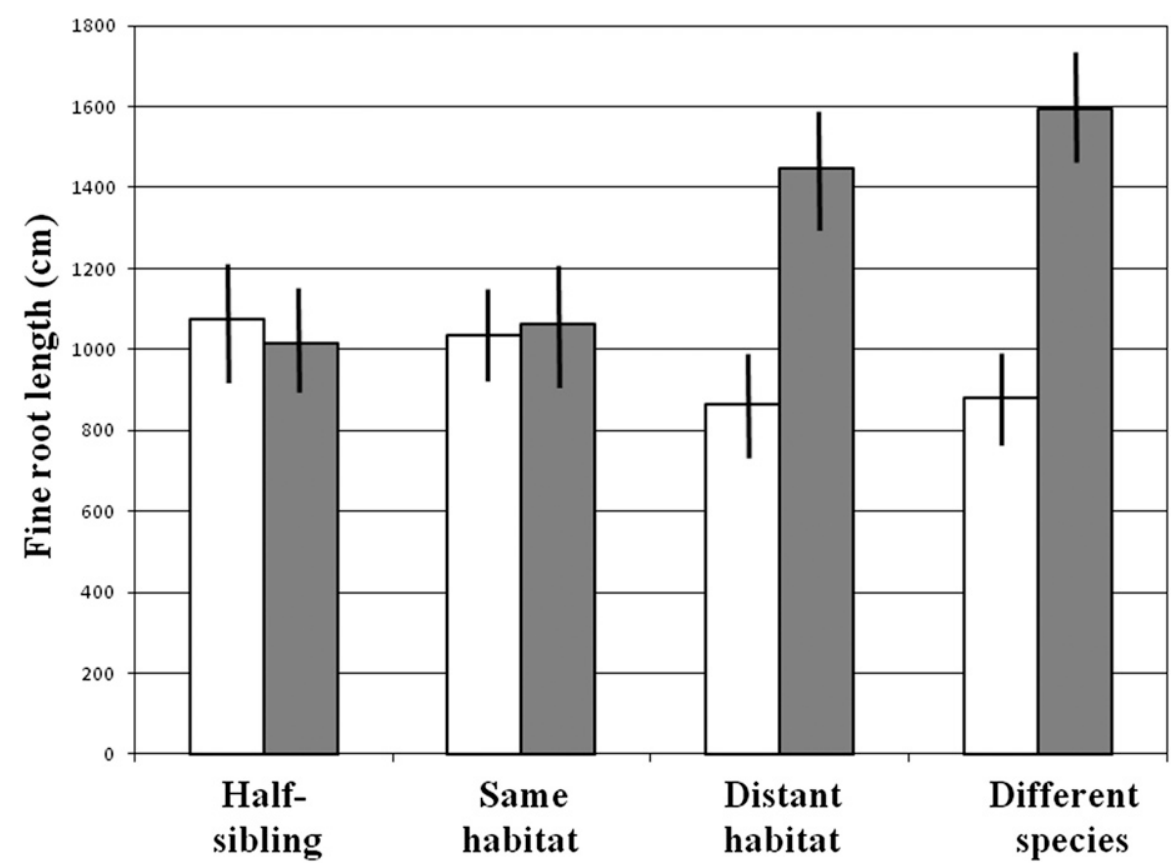

Fig. 3. The length of fine roots in each of two compartments for split-root Cycas edentata plants. Unshaded bars represent roots in the compartment with half-sibling competitors. Shaded bars represent roots in the second compartment in which competitive seedlings were a second half-sibling, a C. edentata from the same habitat, a $C$. edentata from a different habitat, or a Cycas nitida. Means $\pm \mathrm{SE}, \mathrm{n}=9$.

Table 1. Plant traits of split-root Cycas edentata seedlings grown with one root compartment planted with a half-sibling seedling and the second root compartment planted with a half-sibling, a $C$. edentata seedling from the same habitat, a $C$. edentata seedling from a distant habitat, or a $C$. nitida seedling. ${ }^{2}$

\begin{tabular}{lccccc}
\hline & $\begin{array}{c}\text { Half-sibling } \\
\text { competitor }\end{array}$ & $\begin{array}{c}\text { Same } \\
\text { habitat } \\
\text { competitor }\end{array}$ & $\begin{array}{c}\text { Different } \\
\text { habitat } \\
\text { competitor }\end{array}$ & $\begin{array}{c}\text { Different } \\
\text { species } \\
\text { competitor }\end{array}$ & Significance \\
\hline Stem ht $(\mathrm{mm})$ & $37 \pm 2$ & $36 \pm 2$ & $39 \pm 2$ & $48 \pm 1$ & 0.0006 \\
Stem diam $(\mathrm{mm})$ & $32 \pm 1$ & $32 \pm 2$ & $32 \pm 1$ & $40 \pm 1$ & 0.0001 \\
Leaves per plant & $4.9 \pm 0.2$ & $4.7 \pm 0.2$ & $4.8 \pm 0.3$ & $5.7 \pm 0.2$ & 0.0260 \\
Leaflets per leaf & $11.3 \pm 0.5$ & $11.4 \pm 0.8$ & $12.8 \pm 0.4$ & $14.6 \pm 0.4$ & 0.0005 \\
Leaf area $\left(\mathrm{cm}^{2}\right)$ & $679 \pm 85$ & $653 \pm 97$ & $807 \pm 87$ & $1305 \pm 83$ & 0.0001 \\
Total dry wt $(\mathrm{g})$ & $14.9 \pm 1.8$ & $14.0 \pm 1.6$ & $19.5 \pm 2.0$ & $29.3 \pm 1.4$ & 0.0001 \\
Length proportion $^{\mathrm{y}}$ & $0.95 \pm 0.13$ & $1.03 \pm 0.18$ & $1.69 \pm 0.19$ & $1.81 \pm 0.09$ & 0.0041 \\
Dry wt proportion $^{\mathrm{x}}$ & $0.97 \pm 0.11$ & $0.93 \pm 0.10$ & $1.66 \pm 0.18$ & $1.78 \pm 0.12$ & 0.0001 \\
\hline
\end{tabular}

${ }^{\mathrm{z}}$ Mean $\pm \mathrm{SE}, \mathrm{n}=9$.

${ }^{y}$ Root length second compartment/half-sibling compartment.

${ }^{x}$ Root dry wt second compartment/half-sibling compartment.

cycad species, and aggregations of half-sib competitors result. The roots of these seedlings are confronted by competition with the half-sibs, the maternal parent, and other juvenile and mature cycad plants in the community. In addition, roots of the many other sympatric spermatophyte species in natural habitats add to the countless root encounters. A greater understanding of the factors that influence root communication is needed to more fully appreciate the ecology of these habitats.

My methods here were designed to inform practical applications. In home gardens, botanic gardens, and conservation plantings, managers retain control over layout of the cycad plantings, and those decisions have a direct impact on the nuances of root communication and the resulting plant responses. My methods were not designed to answer questions about the interplay between altruistic and selfish behaviors or if cycad relations with neighbors conform to the kin selection hypothesis or resource partitioning hypothesis (see Cheplick and Kane, 2004; Dudley et al., 2013; File et al., 2012). However, for practical application of this new knowledge, these questions do not need to be answered.

Congregating half-sibs in group plantings in botanic gardens is an approach that simplifies mapping and spatial data management. However, my results indicate this approach may limit plant growth, especially root growth, below that which would occur if the individual cycad plants were planted adjacent to non-relatives. These concepts are at the core of recent research on how polycultures increase plant growth above that of monocultures (Laclau et al., 2013; Lang' at et al., 2013; Postma and Lynch, 2012).

Most cycad horticulturists plant seeds in community batches, and this approach generates germinating seedlings that experience immediate root competition with halfor full siblings. For common species with copious amounts of seeds available on the market, the fact that this approach may diminish plant growth may be of negligible consequence if the seedlings are separated into individual containers at a relatively young age. However, when growing rare cycad species, every means by which a horticulturist can improve plant health deserves consideration (Calonje et al., 2010). For these rare species, my results indicate sown seeds should be provided with a germinating environment that is devoid of close relatives.

An extreme example of an endangered cycad species is Encephalartos woodii Sander, a species only known from male plants collected in one locality in South Africa in 1916 (Donaldson, 2010). Cloned individuals of this cycad are highly valuable on the international market and difficult to acquire. Until more is learned about cycad root communication and competition, gardens with more than one $E$. woodii individual, or with multiple cloned individuals from a single genotype of any cycad species, may improve plant growth by refraining from planting the group of cloned individuals as close neighbors.

Plants compete for nutrients by maximizing root length (Craine and Dybzinski, 2013; Ostonen et al., 2007). This can be achieved by producing thinner roots such that a fixed amount of biomass generates increased root length or by increasing deployment of biomass to produce more root growth where edaphic signals inform the plant to become more competitive. In the context of this study, specific root length was not influenced by neighbor identity. However, roots of $C$. edentata seedlings from a distant habitat and roots of $C$. nitida seedlings informed these C. edentata seedlings to deploy more biomass for increasing root length in the vicinity of the competitor's roots.

Biomass allocated for root growth and measured root length were not different in compartments with half-sibs and compartments with a close relative from a mother located $53 \mathrm{~m}$ away but was increased in compartments with a $C$. edentata seedling from a mother located $130 \mathrm{~km}$ away. Therefore, kin cooperation was extended beyond the limits of the half-sib relationship within the same habitat but not to the distant habitat. With the exception of narrowly endemic species, many cycad taxa can exhibit an extensive native range (Norstog and Nicholls, 1997). For example, C. edentata and C. nitida habitats are located on many Philippine islands, and open ocean or terrestrial environments separate the areas of occupancy. These taxa provide an opportunity to use a range of distances from a target plant to determine the distance to which kin cooperation is extended beyond the limits of the same habitat. This knowledge would improve conservation decisions in terms of which genotypes to conserve and how to design the planting layout for ex situ germplasm maintenance. 
Plants display a myriad of plastic responses to improve performance during competition for soil resources. Sophisticated detection of neighbor root identity is the first step for eliciting these plastic responses. This initial cycad study confirmed neighbor identity recognition capability but provokes the need for further research. For example, that root/shoot biomass allocation was not influenced by the treatments was a consequence of the splitroot approach in this pilot study. Although the compartments containing non-relative roots expressed overyielding of the target plant's roots, these same plants compensated by decreasing root growth in the compartments containing half-sibs. Direct competition studies with unmanipulated paired seedlings competing for limited soil resources would generate results that would better determine the true influence of neighbor identity on root/shoot biomass allocation. Quantifying soil-derived resources sequestered within these competing plants would increase our understanding of altruistic vs. selfish behaviors. Other potential issues for research include self vs. non-self root recognition, clonal vs. sibling root recognition and competition, and root exudates or volatile organic chemicals that comprise the arsenal of tools used for cycad root communication. Root architecture is also responsive to the presence of neighbor roots in a manner that is distinct from biomass allocation (Nord et al., 2011); therefore, determining root architecture responses to neighbor roots would also increase our understanding of cycad root biology.

\section{Literature Cited}

Axelrod, R. and W.D. Hamilton. 1981. The evolution of cooperation. Science 211:1390-1396.

Broz, A.K., C.D. Broeckling, C. De-La-Pena, M.R. Lewis, E. Greene, R.M. Callaway, L.W. Sumner, and J.M. Vivanco. 2010. Plant neighbor identity influences plant biochemistry and physiology related to defense. BMC Plant Biol. 10:115.

Calonje, C., C. Husby, and M. Calonje. 2010 Germination and early seedling growth of rare Zamia spp. in organic and inorganic substrates: Advancing ex situ conservation horticulture. HortScience 45:679-683.

Cheplick, G.P. and K.H. Kane. 2004. Genetic relatedness and competition in Triplasis purpurea (Poaceae): Resource partitioning or kin selection? Intl. J. Plant Sci. 165:623-630.

Craine, J.M. and R. Dybzinski. 2013. Mechanisms of plant competition for nutrients, water and light. Funct. Ecol. 27:833-840.

Donaldson, J.S. 2010. Encephalartos woodii. In: IUCN 2013. IUCN red list of threatened species. Version 2013.1. 3 Aug. 2013. <http:// www.iucnredlist.org>.

Dudley, S.A., G.P. Murphy, and A.L. File. 2013. Kin recognition and competition in plants. Funct. Ecol. 27:898-906.

Falik, O., P. Reides, M. Gersani, and A. Novoplansky. 2003. Self/non-self discrimination in roots. J. Ecol. 91:525-531.

File, A.L., G.P. Murphy, and S.A. Dudley. 2012. Fitness consequences of plants growing with siblings: Reconciling kin selection, niche partitioning and competitive ability. Proc. Royal Soc. B-Biological Sci. 279:209-218.

Gruntman, M. and A. Novoplansky. 2004. Physiologically mediated self/nonself discrimination in roots. Proc. Natl. Acad. Sci. USA 101:38633867.

Hamilton, W.D. 1964a. The genetical evolution of social behavior. I. J. Theor. Biol. 7:1-16.

Hamilton, W.D. 1964b. The genetical evolution of social behavior. II. J. Theor. Biol. 7:17-52.

Holzapfel, C. and P. Alpert. 2003. Root cooperation in a clonal plant: Connected strawberries segregate roots. Oecologia 134:72-77.

Laclau, J.-P., Y. Nouvellon, C. Reine, J.L.M. Gonçalves, A.V. Krushe, C. Jourdan, G. le Maire, and J.-P. Bouillet. 2013. Mixing Eucalyptus and Acacia trees leads to fine root over-yielding and vertical segregation between species. Oecologia 172:903-913.
Lang'at, J.K.S., B.K.Y. Kirui, M.W. Skov, J.G. Kairo, M. Mencuccini, and M. Huxham. 2013. Species mixing boosts root yield in mangrove trees. Oecologia 172:271-278.

Lankinen, A. 2008. Root competition influences pollen competitive ability in Viola tricolor: Effects of presence of a competitor beyond resource availability? J. Ecol. 96:756-765.

Lindström, A.J., K.D. Hill, and L.C. Stanberg. 2008. The genus Cycas (Cycadaceae) in the Philippines. Telopea (Syd.) 12:119-145.

Mahall, B.E. and R.M. Callaway. 1992. Root communication mechanisms and intracommunity distributions of two Mojave Desert shrubs. Ecol. 73:2145-2151.

Mahall, B.E. and R.M. Callaway. 1996. Effects of regional origin and genotype in intraspecific root communication in the desert shrub Ambrosia dumosa (Asteraceae). Amer. J. Bot. 83:93-98.

Maina, G.G., J.S. Brown, and M. Gersani. 2002. Intra-plant versus inter-plant root competition in beans: Avoidance, resource matching or tragedy of the commons. Plant Ecol. 160:235247.

Nord, E.A., C. Zhang, and J.P. Lynch. 2011. Root responses to neighbouring plants in common bean are mediated by nutrient concentration rather than self-non-self recognition. Funct. Plant Biol. 38:941-952.

Norstog, K.J. and T.J. Nicholls. 1997. The biology of the cycads. Cornell Univ. Press, Ithica, NY.

Ostonen, I., Ü. Püttsepp, C. Biel, O. Alberton, M.R. Bakker, K. Lõhmus, H. Majdi, D. Metcalfe, A.F.M. Olsthoorn, A. Pronk, E. Vanguelova, M. Weih, and I. Brunner. 2007. Specific root length as an indicator of environmental change. Plant Biosyst. 141:426-442.

Postma, J.A. and J.P. Lynch. 2012. Complementarity in root architecture for nutrient uptake in ancient maize/bean and maize/bean/squash polycultures. Ann. Bot. (Lond.) 110:521-534.

Smit, A.L. (ed.). 2000. Root methods: A handbook. Springer, New York, NY.

Tennant, D. 1975. A test of a modified line intersect method of estimating root length. J. Ecol. 63:995-1001. 